\title{
Inhaltsverzeichnis
}

Vorwort VII

\section{KRIMINALITÄT, KRIMINOLOGIE UND KRIMINALPOLITIK IN DEN NORDISCHEN WOHLFAHRTSSTAATEN}

1. Kriminalität, Kriminologie und Kriminalpolitik in den nordischen Wohlfahrtsstaaten 3

2. Zur Entwicklung der Kriminalpolitik in Finnland ............................ 43

3. Aktuelle Entwicklungstendenzen in der Kriminalpolitik der nordischen Länder 65

4. Neoklassizismus und danach. Zur neuesten Entwicklung der finnischen Kriminalpolitik

5. Zur Kriminal- und Strafrechtspolitik des 21. Jahrhunderts.

Der Blickwinkel eines nordischen Wohlfahrtsstaates und dessen Strafrechtskodifikation (1972-2003)............................. 87

6. Das moderne Strafrecht und das ultima-ratio-Prinzip..................... 107

\section{DAS FINNISCHE STRAFRECHT UND DESSEN GESAMTREFORM}

7. Neues in der finnischen Strafrechtswissenschaft und in den allgemeinen Lehren des finnischen Strafrechts.

8. Die Gesamtreform des finnischen Strafgesetzes: Zielsetzung und Stand der Reformarbeit bis 1991 - insbesondere im Blick auf die erste Phase der Gesamtreform

9. Die jüngsten Entwicklungen im finnischen Strafrecht.

10. Das strafrechtliche Sanktionensystem in der Gesamtreform des Strafrechts. Erfahrungen mit den finnischen Strafgesetzreformen 1972-2007

11. Das Wirtschaftsstrafrecht in der Gesamtreform des Strafrechtes. Erfahrungen mit den finnischen Strafgesetzesreformen 1972-2003 
12. Über die strafrechtliche Verantwortung der juristischen Person und die Organ- und Vertreterhaftung in Finnland 223

III. MEDIZIN(STRAF)RECHT IN FINNLAND

13. Rechtfertigungs- und Entschuldigungsprobleme im Bereich medizinischer Tätigkeit / Problems of Justification and Excuse in the Field of Medicine: A Finnish View

14. Strafrecht und Medizin. Aktuelle Reformpläne in Finnland............... 273

15. Perspektiven der Patientenrechtspolitik in Finnland.......................... 283

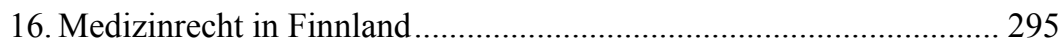

17. Ärzliche Eingriffe und das Selbstbestimmungsrecht

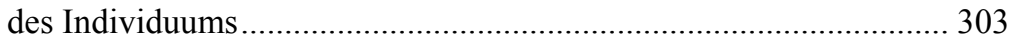

18. Die Knabenbeschneidung als Problem der multikulturellen Gesellschaft

Verzeichnis der Erstveröffentlichungen

Über den Autor 